\title{
XXIX. On the comparative advantages of oil and coal gas
}

\author{
Robert Christison M.D. F.R.S.E. \& Edw. Turner M.D. F.R.S.E.
}

To cite this article: Robert Christison M.D. F.R.S.E. \& Edw. Turner M.D. F.R.S.E. (1825) XXIX. On the comparative advantages of oil and coal gas, Philosophical Magazine Series 1, 66:329, 206-210, DOI: $10.1080 / 14786442508673949$

To link to this article: http://dx.doi.org/10.1080/14786442508673949

$$
\text { 册 Published online: } 10 \text { Aug } 2009 .
$$

Submit your article to this journal $\lceil\pi$

Џ Article views: 3

Q View related articles $\sqsubset$ 


\section{Drs. Christison and Turner on Oil and Coal Gas.}

the contrary the temperature is too high, the combustion is indeed complete and without smoke, but there is a partial destruction of light. (This last point is the most delicate in the art of lighting, since the phænomenon is not directly perceptible by our senses.) In each case, a variable proportion of oil is expended in pure loss. Accordingly, I believe I do not exaggerate in stating, that Argand lamps which give the maximum of light due to the weight of oil they consume, are not less rare than capital prizes in the lottery.

Lighting with gas, on the contrary, is a process comparatively very simple, which dispenses with all care and attention; for the gas which freely escapes under a regular pressure through the orifices of a burner well executed and judiciously proportioned in its dimensions, cannot fail to give an invariable maximum of light.

It is by these considerations only that $I$ have been able to account to myself for a fact which appears very extraordinary at first sight; namely, that 100 pounds of raw oil converted into gas in a large apparatus, such as are constructed by Messrs. Taylor and Martineau of London for the lighting of towns, produce a quantity of light which cannot be produced by Argand lamps without burning at least 130 pounds, sometimes 150 pounds of purified oil ; and it happened to my friend the learned Professor M. Clement Desormes and myself; to make experiments in London on a quite new Paris Argand lamp, which consumed in the proportion of 318 pounds of oil for 100 pounds which its light only represented, in comparison with oil gas.

September, 1825.

XXIX. On the Comparative Advantages of Oil and Coal Gas. By Robent Christison, M.D. F.R.S.E., Professor of Medical Jurisprudence; and EDw. Tunnen, M.D. F.R.S.E. Lecturer on Chemistry, Edinburgh.*

THE paper (read before the Royal Society of Edinburgh, April 18, and May 2, 1825) from which the following extract is given, contains full details of a series of experiments undertaken at Edinburgh, as subordinate, in the first instance, to an inquiry regarding the illuminating power of oil and coal gases, at a time when, from the projected establishment of an oil gas company, the question of the illuminating power of the gases excited an extraordinary interest in that city; and the subject being taken up under the powerful influence of private interest, a variety of statements were published by several scientific gentlemen as the result of their experiments, which, in-

* From the Edinburgh Philosophical Journal, vol. xiii. p. 34. 
stead of rendering the matter clearer, and receiving the confidence of men of science and of the public, differed so widely from what had been previously obtained in London and elsewhere, that a necessity was generally felt for further and more varied experiments, before a question in which such an immense capital was involved throughout the kingdom, could be held as definitively settled.

The experiments relate, 1st, To the instruments employed in the inquiry, and particularly the photometers of Leslie and Rumford; that of the latter was preferred, Mr. Leslie's being found inapplicable, on account of its being affected by non-luminous heat, and not expressing accurately the power of lights differing in colour. 2ndly, To the circumstances which affect the degree of light emitted by the gases during combustion, and which lead to the discovery of the principles on which burners ought to be constructed:- these circumstances are arranged under three heads, the length of the flame, the construction of the burner, and the shape of the glass chimney. 3rdly, The relative Illuminating power of Oil and Coal Gras.

The authors conclude the account of their experiments* by stating that it was not originally their intention to make any remarks on the relative advantages of the two gases in a general point of view. But as the subject has lately led to a long parliamentary investigation, and as very erroneous notions prevail on some matters which have engaged a share of their attention, they add that it may be well to notice it briefly.

ThE question of the relative advantages of oil and coal gas resolves itself into two: The first regards their relative oconomy; The second, their comparative utility.

1. Before we can determine their relative œconomy, it is requisite to settle their average quality. Taking their specific gravity as the ground of comparison, we apprehend that, in small towns, where the cannel coal can be had at a low price, coal gas companies may be able to manufacture a gas of the density of 700. In larger cities, such as Glasgow and Edinburgh, where coal of every kind is dearer, and the cannel coal cannot easily be procured in sufficient quantity, the average

* While the philosophers of Edinburgh were engaged in these interest. ing inquiries, a celebrated Committee in Westminster have had to decide on the same subject. Here, the most practical and conclusive experiments were not, as in the North, on the illuminating power of the gases, but on the power of motives on divers members of the committce. Thus, by a judicious distribution of their shares to some, by making others Directors with large salaries, and by lighting gratuitously the mansions of others, the powerful combination of coal gas companies shtained a decision, not in. deed that their gas was at all equal to oil gas, but that, in the metropolis at least, the latter should not be allowed to come in competition with it.

specific 


\section{Drs. Christison and Turner on Oil and Coal Gas.}

specific gravity of the gas will not exceed 600. And in such a town as London, where the cannel coal can scarcely be procured at all, the average specific gravity will not exceed 450 .

The average specific gravity of oil gas should eventually be the same every where. It is difficult to ascertain what the average is at present, as made by large establishments; but there is no substantial cause why it should fall short of 920 . We have assigned strong reasons, however, for believing that it must be soon improved considerably. This improvement indeed may be no great gain ; for the question will then occur, whether it can be effected without diminishing the quantity of gas in the same proportion with its increase in quality. It is generally supposed that an improvement in the quality of oil gas is necessarily attended by a loss in quantity; but, so far as can be discovered, this idea rests on experiments performed by operatives only, whose authority we are satisfied, from repeated observation, can by no means be relied on. If charcoal is left in the retorts at the end of each charge, it is clear that the gas may be improved by the addition of all this charcoal, without any diminution in quantity; for if it be added to the light carburetted hydrogen, which gives little light, so as to convert it into the olefiant gas, which is powerfully illuminating, the change, it is well known, will take place without any alteration in volume. On the other hand, if good oil gas be exposed to a high temperature, it is partly decomposed, and deposits some of its charcoal. Part of the olefiant gas becomes light carburetted hydrogen, and without any increase in volume; for the volume is not increased unless it is resolved into charcoal and hydrogen. Hence a bad gas may be made from oil, which shall not exceed in quantity the good gas of 'Taylor and Martineau. And in point of fact, we have several times found, when the retorts were choked with charcoal, and the specific gravity of the gas was only 660 , that the quantity fell short of 100 cubic feet per gallon, which is said to be about the average produce when the gas is good. When oil gas has a specific gravity of 910 , charcoal is still found in the retorts. It may therefore be improved by the addition of all this charcoal, and still retain its volume. Besides, it may be possible to improve it by the addition of charcoal from other sources. Hence, while we at present assign to oil gas the average specific gravity of 920 , we cannot help anticipating a considerable improvement and positive gain.

From what has been said of the average quality of coal gas in different quarters of the kingdom, it is clear that the question of its aconomy, compared with oil gas, can be only answered relatively. In Edinburgh and Glasgow, where coal is moderately cheap, and coal gas of good quality, oil gas must 
Drs. Christison and Turner on Oil and Coal Gas. 209

be somewhat dearer; in London, where the coal is dear, and the gas bad, oil gas should be positively cheaper; and in other places the two will be nearly the same in price. This statement is, of course, drawn from our own experiments on their illuminating power, coupled with the well-known computations of Accum, Peckston, Ricardo, and others, regarding their relative cost.

The second element in the question of their relative advantages, is their comparative utility. It is certain that whatever difference may exist between them in this respect must be in favour of oil gas.

In the first place, the quality of the light is superior. It is whiter, and has a peculiar sparkling appearance, superior to that of coal gas. It is therefore a more beautiful light, fitter for the artificial illumination of colours, and not liable to give the human countenance that unpleasant sallow appearance which every one has observed to be caused by coal gas.

An objection has been urged to the employment of gas in general, that it has a disagreeable odour. This objection does not apply at all, unless the gas is unconsumed; for neither oil nor even coal gas, so far at least as our observation goes, emits any odour if properly burnt. But if they escape and mix with the air, their presence is then readily detected by the smell. The odour of oil gas is purely empyreumatic, but quite distinct: we have possessed occasional specimens, which had a faint smell, but we never found it altogether inodorous. The best oil gas appears to have the least smell. The odour of coal gas is of a mixed kind, being in part empyreumatic like oil gas, and partly of an exceedingly offensive nature, like that of sulphuretted hydrogen. In Edinburgh coal gas we have generally observed the empyreuma alone; but frequently the other is perceptible also, and sometimes it prevails to an insufferable degree.

The most serious objection to coal gas arises from the presence of impurities. 'These are, a black matter like tar, and compounds of sulphur,-all derived from the coal itself, and therefore necessarily present originally in every description of coal gas. Without purification, therefore, coal gas could scarcely be used at all; and it becomes a question of importance to determine whether or not the noxious ingredients niay be wholly removed from it. The greater part of the tar is deposited at the works in the proper vessels, but a minute portion does commonly pass over with the gas. It tends to clog the apertures of the burner, and of course soils substances upon which it is deposited. In common shops, where a free current of air is preserved, the effect is hardly noticed; but

Vol. 66. No. 329. Sept. 1825.

$2 \mathrm{D}$

we 


\section{Drs. Christison and Turner on Oil and Coal Gas.}

we suspect that a part of the inconvenience found by jewellers to attend the use of coal gas arises from this cause.

The most formidable of the compounds of sulphur present in coal gas is sulphuretted hydrogen. The presence of this gas is hurtful in two ways. If it escape unburnt, it offends by its insupportable odour, and attacks silver and paint with great readiness. When consumed, it forms sulphurous and sulphuric acids, which may injure the health if habitually inspired, and act chemically on various substances, as on iron and steel. Hence the necessity of removing it entirely from coal gas. On this subject two important questions naturally occur, to both of which we can give a decisive answer. 1st, Can sulphuretted hydrogen be wholly separated from coal gas? and 2dly, when it is removed, Can coal gas be regarded as perfectly free of sulphur?

We are satisfied that sulphuretted hydrogen may be wholly removed; for we have repeatedly examined the Edinburgh coal gas by the most delicate tests, without detecting a trace of it. Of course we do not vouch that it is always equally pure, because the least neglect on the part of the workmen must inevitably cause some sulphuretted hydrogen to escape into the pipes. It is equally certain, however, that coal gas, when completely free of sulphuretted hydrogen, still contains sulphur. On burning a small jet of coal gas, free from sulphuretted hydrogen, so as to collect the fluid formed during the combustion, the presence of sulphuric acid was uniformly detected, demonstrating the existence of some compound of sulphur. What that compound is has not yet beell ascertained; but from its peculiar unpleasant odour, and the circumstances under which it is generated, the sulphur is most probably in combination with carbon, either in the form of the volatile liquid (sulphuret of carbon, as Mr. Brande conjectures), or, what is perhaps more likely, as a gaseous compound, containing a less proportion of sulphur than exists in that liquid.

In whatever state of combination the sulphur may be, it does not affect the salts of lead like sulphuretted hydrogen; nor does it act so readily, if at all, on polished silver and gold. Hence the gas which contains only this impurity will be less injurious when any of it escapes umburnt, than such as contains sulphuretted hydrogen; but since it uniformly yields acid vapours during its combustion, one part of the objection remains in full force.

These various objections, whatever weight they may have, apply to coal gas only.

XXX. $A$ 